\title{
What is the future for sexual and contraceptive services?
}

\section{Su Everett}

Middlesex University, Archway Campus, The Burroughs, London, UK

\section{Correspondence to} Su Everett, Middlesex University, Hendon Campus, London, UK; s.everett@mdx.ac.uk

Received 22 February 2017 Revised 16 May 2017 Published Online First 19 June 2017
CrossMark

To cite: Everett S.J Fam Plann Reprod Health Care 2017:43:234-236.

\section{BACKGROUND}

It is always difficult to write about something you are passionate about objectively, and sexual health is one such subject for me. So, the following is my personal view on the massive changes taking place within sexual health. I do this from a standpoint of having worked in sexual health both as a clinician and a lecturer since 1985 and 1998, respectively, but also as someone who has worked as a practice nurse for 8 years.

There is a nervous edge around sexual health currently, as sexual health services within London are fighting for contracts. This has meant that sexual health services are competing against each other, whereas usually there are close links between sexual health services as staff move between services. If a service wins the contract then their future is assured for the time being. However, if they lose, then their service is unlikely to survive and will only continue in the current format until July 2017, and there will inevitably be job losses. Currently sexual health services that have lost contracts are unable to give information to patients about the future of their service. Already nurses within these departments are leaving sexual health services as they are worried that they might not have a job come July. The loss of expertise will be sorely missed; the specialist skills of health professionals working this area involve identifying and caring for those at risk of grooming, sexual abuse, sexual assault and sex work. It is a special person who works in this area and sensitively listens to, and supports, the men and women who access these services.

Since 2013 Local Authorities have provided contraceptive service funding, but with significant government cutbacks and pressure on Local Authorities' budgets these services are at risk. ${ }^{1}$ One in six Local Authorities have decreased spending on contraception in the 2015/2016 financial year, resulting in job losses. Government funding for the provision of public health has been significantly reduced by an average of $3.9 \%$ per annum in the course of the present parliament. ${ }^{1}$ In tandem with this, National Health Service (NHS) trusts have the burden of large financial deficits, and the need to reduce arrears has never been greater. Sexual health services (previously known as genitourinary medicine) are funded through NHS trusts, and as result of trusts' financial constraints these services have been reduced. ${ }^{1-3}$ Because of these financial constraints, it is seen as more cost effective to reduce the number of sexual health clinics in London rather than retaining them in their current format. However, users often favour sexual health services that they feel identify with their population or cultural group. ${ }^{45}$ Reducing clinical sites does not make service users move to another site, especially if they have a strong attachment to a previous service. The atmosphere in the clinic, and the staff-client relationships, both encourage loyalty in the same way that many of us have a favourite hairdresser or bank. Service users may prefer to attend clinics away from their place of work and or home so that they are anonymous. There is still stigma surrounding sexual health clinics, less than in the 1980 s, but some people still find these clinics difficult places to attend, and as much as they like their general practitioner (GP) they may not want to share sensitive information about sexual practices with them, and this is seen particularly in young men and in Black Minority Ethnic (BME) groups. ${ }^{5} 6$ By reducing clinical services, user choice is restricted.

\section{DO CUTBACKS CREATE FINANCIAL SAVINGS?}

When the first Unprotected Nation was published in 2013 there was concern about reductions within sexual health services, and I think there was an air of disbelief 
that valuable services could be lost. ${ }^{2}$ The Family Planning Association's (FPA's) 2015 Unprotected Nation - An Update on the Financial and Economic Impacts of Restricted Contraceptive and Sexual Services forecasted that the reduction of services in sexual health and contraception would equal a $10 \%$ cut in services in the UK. That time has come and services are being cut. In the short term, it is estimated that for every $£ 1$ of expenditure cut over the next 10 years this will cost the UK $£ 159 .{ }^{3}$ These cuts will thus lead to rising numbers of unwanted pregnancies and an increasing incidence of sexually transmitted infections (STIs), which is why the reduction of services is not a saving. Abortion rates have been constant since 2005, with the number of abortions being 186416 ; the latest abortion rates in 2015 for England and Wales were 185 824. ${ }^{7}$ Contraception reduces abortions and saves money but also reduces the emotional burden to the woman.

The increasing incidence of antibiotic-resistant gonorrhoea has now risen to a total of 34 confirmed cases in England between November 2014 and April 2016, resulting in Public Health England issuing a warning about safer sex and reminding us that they are there to protect and improve the nation's health. ${ }^{8}$ Reducing services will not ensure that the public is protected and this is not the time to reduce services. ${ }^{12}$ The consequence of STIs can be pelvic inflammatory disease and infertility, premature labour and low birth weight babies. These sequelae lead to distress for men and women and financial costs to the NHS.

\section{LOSS OF CLINICAL PLACEMENTS AND EDUCATIONAL TRAINING}

Combined with the loss of sexual health services there has been a reduction in the finance available for training nurses in contraception and sexual health. Following the 2016 'Comprehensive Spending Review' there was a reduction in NHS funds available for continuous professional development training, and the impact of this was reduced funding for contraceptive courses. ${ }^{9}$ The loss of training places will mean that there are fewer nurses with the requisite skills available to work in this clinical area. Sexual health clinics provide training places for GPs and undergraduate nurses and medical students, which is vital in providing a holistic understanding of the men and women we care for.

\section{WHAT ARE THE CONSEQUENCES OF REDUCING SEXUAL HEALTH SERVICES?}

Sexual health services over the last 10 years have increased and are more likely to be integrated so that contraception and STIs can be covered in a single consultation but also have increased accessibility with some open on Sundays. The volume of users who walk through the doors of sexual health service clinics is huge, and as a clinician who has worked in south east, central and north London, I know that I have seen many users who live outside of London and who complain that there are fewer services available in thier local area, and if services are available then they are not open when they get home from work. In 2015 in England there were 435000 STI diagnoses, and syphilis has increased by $20 \%$ and gonorrhoea by $11 \%$ since $2014 .{ }^{10}{ }^{11}$ Increasing incidences of Shigella and lymphogranuloma venereum (LGV) in men who have sex with men (MSM) highlight the increasing number of MSM who are having unprotected sexual intercourse; reducing sexual health services will not help this situation. ${ }^{10} 11$ By far the greatest group of men and women affected by STIs is BME groups, with the incidence of gonorrhoea and chlamydia being three times higher and the incidence of trichomonas being nine times higher than the general population. ${ }^{10}$

The Social Exclusions Unit's work in 1999 on teenage pregnancy strongly advocated sexual health services to reduce the marginalisation of young men and women in our society. ${ }^{12}$ The systematic dismantling of sexual health services will only increase the marginalisation of socially excluded men and women, and as a result increase abortion and STI rates. ${ }^{1}$

Where will men and women go if there are reduced sexual health services? It is likely that sexual health will get pushed into GP services, which are already overextended and do not necessarily have sufficient sexual health specialist knowledge. Research shows that young men and BME groups prefer specialist sexual health services, so will these groups be lost to services or will they turn to self-help and the internet for support? ${ }^{56}$ By reducing specialist services, there will be a gap in experience and skills, resulting in fewer specialist nurses and doctors. This will mean that when STI and abortion rates increase there will not be the necessary skill set available to develop services. Sadly, it is men and women who will suffer trying to obtain help and support for their sexual health needs. If, like me, you are concerned about the changes within sexual health, you need to voice your concerns: we need to become louder in our opposition to reducing services.

Correction notice This paper has been amended since it was published Online First. Owing to a scripting error, some of the publisher names in the references were replaced with 'BMJ Publishing Group'. This only affected the full text version, not the PDF. We have since corrected these errors and the correct publishers have been inserted into the references.

\section{Competing interests None declared.}

Provenance and peer review Not commissioned; externally peer reviewed.

(C) Faculty of Sexual and Reproductive Healthcare of the Royal College of Obstetricians and Gynaecologists (unless otherwise stated in the text of the article) 2017. All rights reserved. No commercial use is permitted unless otherwise expressly granted. 


\section{REFERENCES}

1 Advisory Group on Contraception. Private Lives, Public Health: The Changing Shape of Contraceptive Services in England Post 2013: Advisory Group on Contraception, 2016.

2 Brook and Family Planning Association (FPA). Unprotected Nation 2013 - The Financial and Economic Impacts of Restricted Contraceptive and Sexual Health Services. London, UK: Brook and FPA, 2013.

3 Family Planning Association (FPA). Unprotected Nation 2015 - An Update on the Financial and Economic Impacts of Restricted Contraceptive and Sexual Health Services. London, UK; FPA, 2015.

4 Koester KA, Collins SP, Fuller SM, et al. Sexual healthcare preferences among gay and bisexual men: a qualitative study in San Francisco, California. PLoS One 2013;8:e71546.

5 Lewis DA, McDonald A, Thompson G, et al. The 374 clinic: an outreach sexual health clinic for young men. Sex Transm Infect 2004;80:480-483.
6 Mens Health Forum. The Gender and Access of Health Services Study. Final Report. London, UK: Department of Health, 2008.

7 Department of Health. Abortion Statistics, England and Wales: 2015. London, UK: Department of Health, 2016.

8 Public Health England. Safe sex reminder as antibiotic resistant gonorrhoea investigations continue: Public Health England.

9 Department of Health. Spending Review and Autumn Statement 2015. London, UK: Department of Health, 2015.

10 Public Health England (PHE). Sexually transmitted infections in England infographics. 2016. https://www.gov. uk/government/statistics/sexually-transmitted-infections-stisannual-data-tables accessed 4 May 2017.

11 Public Health England. Health Protection Report. Infection Report. 10. Number 22: Public HealthEngland, 2016.

12 Social Exclusion Unit. Teenage Pregnancy. London, UK: Department of Health, 1999. 